\title{
Enfermedad de Chagas crónica.Ausencia de Triatoma infestans intradomiciliario y persistencia de Trypanosoma cruzi circulante post-terapia
}

\author{
INÉS ZULANTAY*, FRANCISCA BOZÁN*, CARLOS SALAS*, NICOLÁS ZILLERUELO*, \\ ANTONIO OSUNA**, LUIS C. GIL***, JORGE RODRÍGUEZ****, ANTONIO ROJAS*, \\ JOSE L. EGEA* y WERNER APT*
}

\section{CHRONIC CHAGAS DISEASE. ABSENCE OF INTRADOMICILIARY Triatoma infestans AND PERSISTENCE OF CIRCULATING POST-THERAPY Trypanosoma cruzi}

In 1999 Chile declare no vectorial transmission of Chagas disease. On the other hand, the development of dwelling policy which include endemic rural zones, have obtained important advances in human groups with height deficiency of habitability. This epidemiological situation was studied 10 years after therapy, in 37 chronic chagasic patients from rural zones of the VI Region, by an epidemiologic inquest (pre and post-therapy) and parasitological evolution (post therapy). The inquest included: knowledge of the vector, presence of triatomines in the dwelling antecedents of have been bitten by triatomines, and construction materials of the dwellings. The parasitological evolution was performed by xenodiagnosis (XD) (37 cases) and Polimerase Chain Reaction (PCR) in peripherical blood (34 cases). The results of the epidemiological survey evidenced important changes of the quality of the rural dwelling of the treated chagasic patients, while, in relation to parasitemia, circulant Trypanosoma cruzi was detected in the $89.2 \%$ of the cases. (37.8\%) and $88.2 \%$ by XD and PCR respectively. It is concluded that the persistence of the parasite after therapy is not relationated with the presence of intradomiciliary Triatoma infestans.

Key words: Trypanosoma cruzi, Triatoma infestans, Enfermedad de Chagas.

\section{INTRODUCCIÓN}

En Chile, el área endemo-enzoótica de la enfermedad de Chagas se distribuye en sectores rurales y periurbanos de las seis primeras regiones político-administrativas, más la Región Metropolitana, siendo las regiones III y IV consideradas hiperendémicas ${ }^{1}$. Entre otras consideraciones, un promedio general de infección humana del $12 \%$ según xenodiagnóstico y del $19 \%$ según serología ${ }^{2}$, con aproximadamente 63.000 viviendas rurales o peri-urbanas sujetas a actividades anti-Triatoma infestans ${ }^{3}$, fundamentó la inclusión de nuestro país en el Programa

\footnotetext{
* Laboratorio de Parasitología Básico-Clínico. Programa de Biología Celular y Molecular. Instituto de Ciencias Biomédicas. Facultad de Medicina. Universidad de Chile.

** Instituto de Biotecnología. Facultad de Ciencias. Universidad de Granada. España.

*** Hospital Clínico de la Universidad de Chile.

**** Escuela de Salud Pública. Facultad de Medicina. Universidad de Chile.
} 
Intergubernamental del Cono Sur para la Eliminación de la Transmisión Vectorial y Transfusional de la Enfermedad de Chagas ${ }^{4}$. Tras la aplicación de esta iniciativa, se certificó a Chile como el segundo país que ha interrumpido la transmisión vectorial de la enfermedad de Chagas 5 .

Paralelo a estos importantes avances, la Reacción en Cadena de la Polimerasa (PCR) se ha constituido en una promisoria herramienta de diagnóstico, amplificando ADN de Trypanosoma cruzi desde regiones altamente repetidas del genoma del parásito ${ }^{6}$, demostrando alta sensibilidad $^{7-9}$.

Otro aspecto ampliamente abordado por diferentes grupos de investigación, ha sido la quimioterapia de la enfermedad de Chagas crónica, etapa para la cual, se ha sugerido investigar medicamentos diseñados para afecciones no relacionadas que exhiban actividad contra T. cruzi y sean inocuos para el hombre ${ }^{10,11}$

En el presente estudio, se asocia la condición parasitológica determinada por XD y PCR, con algunos antecedentes epidemiológicos relacionados con el hábitat intradomiciliario de T. infestans en chagásicos crónicos tratados.

\section{MATERIAL Y MÉTODOS}

Se evaluaron 37 pacientes chagásicos crónicos procedentes de zonas rurales de la IV Región, 17 hombres y 22 mujeres (promedio de edad 43 años), tratados con allopurinol $(n=11)$ o itraconazol $(n=26)$ en el año 1992, según protocolo descrito ${ }^{12,13}$. Los casos se seleccionaron de acuerdo a los siguientes criterios: haber sido encuestados antes y diez años después de concluida la terapia), que contaran con muestras de sangre periférica para PCR y se les hubiera aplicado XD en condiciones de post-terapia. Finalmente, que su procedencia correspondiera a localidades rurales endémicas incorporadas a programas de control del vector.

La encuesta epidemiológica aplicada en los años 1992 (previo a la terapia) y 2002 (diez años post-terapia) incluyó información acerca de: conocimiento del vector, presencia de $T$. infestans en el domicilio actual, antecedentes de haber sido picado por triatominos y, en relación a la infraestructura de la vivienda, material de muros y techo. A todos aquellos pacientes que declararon en el año 1992, infestación domiciliaria por $T$. infestans, se les consultó en forma anexa, si realizaron la denuncia a la autoridad sanitaria correspondiente y la fecha aproximada de erradicación del vector en el domicilio y peridomicilio.

Se aplicó, en condiciones de post-terapia (2002), dos cajitas de xenodiagnóstico (XD), según técnica descrita previamente ${ }^{14}$. Cada una de ellas contenía siete ninfas de tercer estadio de $T$. infestans libres de infección. Las cajas fueron mantenidas a $27^{\circ} \mathrm{C}$, realizando posterior examen microscópico de la muestra fecal de los insectos a los 30, 60 y 90 días de incubación, en búsqueda de las formas tripomastigotas de T. cruzi.

A cada paciente en condiciones de post-terapia, se le extrajo $10 \mathrm{cc}$ de sangre venosa, distribuidos de la siguiente manera: $5 \mathrm{ml}$ para PCR, recibidos en buffer Guanidina $\mathrm{HCl} 6 \mathrm{M}$ y EDTA $0,2 \mathrm{M}$ usados como preservante y anticoagulante respectivamente, y $5 \mathrm{ml}$ en tubo sin anticoagulante para la obtención de suero y posterior análisis por serología convencional. Ambas muestras fueron alicuotadas y mantenidas a $-20^{\circ} \mathrm{C}$ hasta su uso.

Se determinaron los niveles de anticuerpos IgG contra antígenos totales de $T$. cruzi mediante las técnicas de Inmunofluorescencia Indirecta (IFI) y ELISA. Se consideró una reacción de IFI positiva cuando el título fue igual o mayor a 1/20. Para ELISA, el límite discriminativo de positividad se calculó como el producto de la media aritmética de los controles negativos más tres desviaciones estandar ${ }^{15}$.

Con el fin de extraer el ADN kinetoplastídico (kADN) de T. cruzi, para realizar PCR, las muestras fueron precipitadas y lavadas con etanol absoluto y etanol $70 \%$, respectivamente, seguida de un proceso de digestión con TRIS $(0,01 \mathrm{M})$, EDTA $(0,005 \mathrm{M})$, $\operatorname{SDS}(0,5 \%)$ y proteinasa $\mathrm{K}(20 \mathrm{mg} / \mathrm{ml})$. Las muestras fueron sometidas a un proceso de desproteinización con fenol-cloroformo-alcohol isoamílico seguido de un proceso de precipitación del ADN con acetato de amonio 3M y etanol absoluto. Una vez finalizada esta etapa, el ADN fue purificado en columnas de Sephadex G-25 y utilizado como molde para la reacción de PCR. La mezcla de reacción estaba compuesta por $5 \mu \mathrm{l}$ de la muestra, $3 \mu \mathrm{l}$ de los oligonucleótidos 121 (5'AAATAATGTACGGG(T/G)GAGATGCATGA3') y 122 (5'GGTTCGATTGGGGTTGGTGTAATATA3'), a una concentración de $25 \mu \mathrm{M}, 5 \mu \mathrm{l}$ de buffer de Taq polimerasa (que contiene Tris- $\mathrm{HCl} \mathrm{pH} 8,867$ $\mathrm{mM}, 16,6 \mathrm{mM}$ de $\left(\mathrm{NH}_{4}\right)_{2} \mathrm{SO}_{4}, 6,7 \mathrm{mM}$ de $\mathrm{MgCl}_{2}$, 
$10 \mathrm{mM}$ 2-Mercaptoetanol), $0,5 \mu \mathrm{l}$ de BSA, $5 \mu \mathrm{l}$ $(0,4 \mathrm{mM})$ de los cuatro dNTP (dATP, dCTP, dGTP, dTTP), $31 \mu$ de agua bidestilada en un volumen final de $50 \mu \mathrm{l}$, además de $4 \mathrm{U}$ Taq polimerasa $(0,5$ $\mu \mathrm{l})$. Esta mezcla fue cubierta por $80 \mu \mathrm{l}$ de aceite mineral. El programa de amplificación de la reacción de PCR consistió en: dos ciclos iniciales de $98^{\circ} \mathrm{C}$ por 1 minuto y $64^{\circ} \mathrm{C}$ por 2 minutos; 33 ciclos intermediarios de $94^{\circ} \mathrm{C}$ por 1 minuto y $64^{\circ} \mathrm{C}$ por 1 minuto y un ciclo final de $72^{\circ} \mathrm{C}$ por 10 minutos. Finalmente, $10 \mu \mathrm{l}$ del amplificado se mezclaron con $4 \mu \mathrm{l}$ de buffer de carga que contenía xylenxianol y azul de bromofenol y se sometieron a electroforesis en gel de agarosa al 2\% (en buffer Tris Borato EDTA $1 \mathrm{x})$. El gel fue teñido con bromuro de etidio $(5 \mu \mathrm{g} /$ $\mathrm{ml}$ ) por 10 minutos y luego fotografiado. Se consideró como una reacción positiva para PCR, la aparición de una banda de 330 pb correspondiente a kADN de $T$. cruzi $i^{16-18}$.

Para el análisis estadístico de los datos se utilizó el paquete estadístico SPSS. La prueba utilizada para evaluar los cambios fue Mc Nemar y Fisher para analizar asociación. El nivel máximo de signi-ficación se estableció en 0,05 .

\section{RESULTADOS}

En el año 1992, como se observa en la Tabla 1, el 89,2\% de los encuestados manifestó conocer a los triatominos, el 18,9\% refirió presencia de T. infestans en el domicilio actual y el $83,8 \%$ tenía la seguridad de haber sido picado por ellos. En relación a la vivienda, el 48,6\% de los muros de las habitaciones de los pacientes chagásicos eran de adobe, el $13.5 \%$ de cemento o adobe estucado y el $29,7 \%$ de madera. En relación al material del techo de la vivienda, el 59,5\% era de zinc, el $27 \%$ de pizarreño y el 10,8\% de quincha (paja y barro). En la encuesta aplicada a los mismos pacientes en el año 2002, se mantuvo el porcentaje en relación al conocimiento del vector $(89,2 \%)$, ninguno de los casos reportó presencia de $T$. infestans domiciliario o peri-domiciliario $(\mathrm{p}=$ $0,0086)$ y el $81,8 \%$ manifestó haber sido picado por las vinchucas. Con respecto al material de los muros de las habitaciones en el año 2002, sólo el $8,1 \%$ era de adobe ( $\mathrm{p}=0,00001)$, el $48,6 \%$ de madera $(\mathrm{p}=0,0086)$ y el $32,4 \%$ de cemento o adobe estucado $(p=0,0086)$. Para el mismo

Tabla 1. Antecedentes epidemiológicos de 37 chagásicos crónicos procedentes de zonas rurales de la IV Región tratados con alopurinol o itraconazol en condiciones de pre-terapia (año 1992) y diez años después de concluida la terapia (año 2002)

\begin{tabular}{lrrrrr}
\hline & $\mathbf{n}$ & $\mathbf{1 9 9 2}$ & $\mathbf{2 0 0 2}$ & \\
& & & & & \\
\hline Conoce las vinchucas & 33 & 89,2 & 33 & 89,2 & $\mathrm{Palor} \mathbf{P}$ \\
$\mathrm{Si}$ & 4 & 10,8 & 4 & 10,8 & \\
No & & & & & \\
Existen en el domicilio actual & 7 & 18,9 & 0 & 0,0 & $\mathrm{P}=0,0086$ \\
$\mathrm{Si}$ & 30 & 81,1 & 37 & 100,0 & \\
No & & & & & \\
Ha sido picado por vinchucas & 31 & 83,8 & 30 & 81,8 & $\mathrm{P}>0,05$ \\
$\mathrm{Si}$ & 6 & 16,2 & 7 & 18,2 & \\
No & & & & & \\
Paredes habitaciones de la vivienda & 18 & 48,6 & 3 & 8,1 & $\mathrm{P}=0,00001$ \\
Adobe & 5 & 13,5 & 12 & 32,4 & $\mathrm{P}=0,0086$ \\
Cemento o adobe estucado con cemento & 1 & 2,7 & 1 & 2,7 & $\mathrm{P}>0,05$ \\
Ladrillo & 11 & 29,7 & 18 & 48,6 & $\mathrm{P}=0,0086$ \\
Madera & 2 & 5,4 & 3 & 8,1 & $\mathrm{P}>0,05$ \\
Volcanita & & & & & \\
Techo de la vivienda & 22 & 59,5 & 25 & 67,6 & $\mathrm{P}>0,05$ \\
Zinc & 10 & 27,0 & 12 & 32,4 & $\mathrm{P}>0,05$ \\
Pizarreño & 4 & 10,8 & 0 & 0,0 & $\mathrm{P}>0,05$ \\
Quincha & 1 & 2,7 & 0 & 0,0 & $\mathrm{P}>0,05$ \\
Madera & & & & &
\end{tabular}


período, no se reportaron techos de quincha ( $\mathrm{p}$ $>0,05)$.

En la Tabla 2, se observan los resultados de la evaluación parasitológica realizada en los mismos pacientes encuestados, diez años después de concluida la terapia con alopurinol o itraconazol. Se detectó la presencia de T. cruzi en 33 de los 37 casos encuestados $(89,2 \%)$ al utilizar XD, PCR o ambas técnicas en forma simultánea. Las sensibilidades obtenidas para los dos métodos fueron del 37,8\% (14/37) y 88,2\% (19/34) para XD y PCR, respectivamente.

Tabla 2. Resultados de XD y PCR obtenidos en 37 chagásicos crónicos procedentes de zonas rurales de la IV Región tratados con itraconazol o allopurinol en seguimiento prolongado (diez años post-terapia)*

\begin{tabular}{llll}
\hline $\mathbf{N}$ & XD & PCR & \% \\
\hline 11 & + & + & 29,7 \\
19 & - & + & 51,4 \\
4 & - & - & 10,8 \\
3 & + & ND & 8,1 \\
\hline
\end{tabular}

$* \mathrm{P}>0,05$

\section{DISCUSIÓN}

El Programa Nacional del Control del Vector de la enfermedad de Chagas en Chile, impulsado por el Ministerio de Salud, se inicia en el Servicio de Salud Coquimbo en el año 1980, permitiendo mantener bajo control la presencia de $T$. infestans en el $80 \%$ de las viviendas de áreas endémicas, con una reinfestación promedio del 3,4\% $\%^{3,19}$. El Programa Intergubernamental del Cono Sur para la Eliminación de la Transmisión Vectorial y Transfusional de la Enfermedad de Chagas ${ }^{4}$, consolidó tales esfuerzos. El presente estudio, realizado en zonas rurales de la IV Región de nuestro país, evidencia que un importante porcentaje de pacientes en los cuales se ha comprobado la infección por $T$. cruzi, conoce a los triatominos y refiere haber sido picado por ellos. Todos aquellos casos, que en la encuesta aplicada en 1992 declararon infestación domiciliaria por triatominos, fueron estimulados a realizar la denuncia correspondiente para concretar la intervención del Programa sobre el Ambiente. Tras este hecho, la totalidad de los afectados, informa que se realizaron actividades de investigación triatomínica, ataque y vigilancia, logrando erradicar al insecto en sus domicilios y peridomicilios en un período no inferior a dos años. Es así como, en el año 2002, tal como se observa en la Tabla 1, el 100\% de los casos reporta ausencia de $T$. infestans en sus viviendas. Con respecto a la información entregada por los encuestados en relación a la picadura de triatominos, es posible que el $16,2 \%$ que manifiesta no haber tenido contacto con el vector, y aún así, estar infectados por T. cruzi, se deba a: transmisión transplacentaria y transmisión vectorial que no fue percibida por el infectado (edad, hábitos nocturnos del triatomino, picadura indolora, ausencia de lesiones cutáneas, etc). Por otra parte, es interesante observar los cambios que durante la década 1992-2002, tuvo el material de construcción de muros y techos de las viviendas de los pacientes encuestados. En el año 1992, un 48,6\% de los casos vivía en casas de adobe. Por el contrario, en el año 2002, un 32,4\% posee viviendas con paredes de cemento o adobe estucado y un $48,6 \%$ paredes de madera. Tal situación se ha visto favorecida por políticas habitacionales desarrolladas para el área rural de nuestro país, que han permitido importantes avances en grupos humanos que presentaban graves deficiencias de habitabilidad (materialidad o saneamiento $)^{20}$. El otorgamiento de subsidios rurales permitió que dicho déficit disminuyera al $9,9 \%$ en el año 1998, en comparación con el $16,7 \%$ informado para el año $1990^{21}$. Junto a ello, la cobertura de viviendas rurales electrificadas en la IV Región ascendió de un $54 \%$ a un $79 \%$ entre los años 1992 y $2002^{22}$.

Después de diez años post-terapia (año 2002), todos los pacientes mantienen la serología convencional positiva (IFI y ELISA) y en el $89,2 \%$ de los casos se evidencia mediante XD o PCR o ambos, la persistencia de $T$. cruzi circulante. La mayor sensibilidad de PCR en comparación con XD obtenida en el presente estudio, ya ha sido previamente reportada $a^{6,23}$, validando su uso como herramienta de evaluación de eficacia quimioterapéutica ${ }^{17,18,24}$. Al correlacionar los resultados epidemiológicos y parasitológicos, diez años después de concluida la terapia, es posible sostener, que la persistencia de la parasitemia no está directamente relacionada con la exposición a T. infestans intradomiciliario, puesto que en comparación con el año 1992, las condiciones favorables para su desarrollo por 
efectos de los Programas de Control del Vector y mejoramiento de la vivienda rural, se han visto disminuidas. No obstante, estos resultados no son suficientes para determinar la real eficacia de drogas antichagásicas en la etapa crónica de la enfermedad de Chagas, puesto que sería necesario considerar otros aspectos relevantes tales como, la cuantificación de kADN de $T$. cruzi en condiciones de pre y post-terapia, evaluación de la eventual cepa-especificidad a drogas recientemente descrita en estudios experimentale ${ }^{25} \mathrm{y}$ el establecimiento de la existencia o ausencia de correlación entre la parasitemia y la evolución clínica en seguimiento prolongado post-terapia.

\section{RESUMEN}

En el año 1999, se certificó en Chile la interrupción de la transmisión vectorial de la enfermedad de Chagas. Por otra parte, el desarrollo de políticas habitacionales, que incluyen zonas rurales endémicas, han logrado importantes avances en grupos humanos que presentaban graves deficiencias de habitabilidad. En esta situación epidemiológica, se estudió 10 años después de la terapia, a 37 chagásicos crónicos procedentes de zonas rurales de la IV Región, mediante encuesta epidemiológica (pre y postterapia) y evaluación parasitológica (post-terapia). La encuesta incluyó: conocimiento del vector, triatominos en el domicilio actual, antecedentes de haber sido picado por triatominos y material de la construcción de la vivienda. La evaluación parasitológica se realizó mediante xenodiagnóstico (XD) (37 casos) y Reacción en Cadena de la Polimerasa (PCR) en sangre periférica (34 casos). Los resultados de la encuesta epidemiológica evidenciaron cambios importantes en la calidad de la vivienda rural de los chagásicos tratados, mientras que, en relación a la parasitemia, se detectó Trypanosoma cruzi circulante en el 89,2\% de los casos $(37,8 \%$ y $88,2 \%$, mediante XD y PCR, respectivamente). Se concluye que la persistencia del parásito en condiciones post-terapia, no está relacionada con la presencia de Triatoma infestans intradomiciliario.

\section{REFERENCIAS}

1.- SCHENONE H, CONTRERAS M C, SALINAS P et al. Epidemiología de la enfermedad de Chagas en Chile. Frecuencia de la infección humana por Trypanosoma cruzi por grupos de edad y regiones. Bol Chil Parasitol 1995; 50: 84-6.

2.- APT W, REYES H. Aspectos epidemiológicos de la enfermedad de Chagas en Chile. Distribución geográfica, índices de infección en vectores y en humanos. Parasitol al Día 1986; 10: 94-101.

3.- CORREA V et al. Control de Vectores. Taller sobre erradicación o control de la enfermedad de Chagas en Chile. Santiago, Chile. 1991. 70 pág.

4.- OPS. Iniciativa de los países del Cono Sur. Primera Reunión de la Comisión Intergubernamental para la Eliminación del Triatoma infestans y la interrupción de la transmisión de la tripanosomiasis americana por transfusión. 1992. Buenos Aires, Argentina. Doc OPS/ PNSP/92.18.

5.- WORLD HEALTH ORGANIZATION. WHO Chagas's disease interrupted in Chile. TDR News. 2000; 61, pp10.

6.- CHIARI E. Chagas'disease diagnosis using polimerase chain reaction, hemoculture and serologic methods. Mem. Inst. Oswaldo Cruz, Rio de Janeiro 1999; 94: Suppl 1: 299-300.

7.- BRITTO C, CARDOSO M A, MONTEIRO VANNI C $\mathrm{M}$ et al. Polymerase chain reaction detection of Trypanosoma cruzi in human blood samples for diagnosis and treatment evaluation. Parasitol 1995; 110: 241-7.

8.- JUNQUEIRA A C, CHIARI E, WINCKER P. Comparison of the polymerase chain reaction with two classical parasitological methods for the diagnosis of Chagas disease in a endemic region of northeastern Brazil. Trans Roy Soc Trop Med Hyg 1996; 90: 129 32.

9.- BRITTO C, CARDOSO A, MARQUES P et al. Polymerase chain reaction detection: New insights into the diagnosis of chronic Chagas disease. Mem Inst Oswaldo Cruz 1999 (Suppl 1): 305-6.

10.- MARR J. Purine analogs: chemotherapeutic agents in leishmaniasis and American trypanosomiasis. J Lab Clin Med 1990; 118: 111-9.

11.- MCCABE R, REMINGTON J, ARAUJO F. In vitro and in vivo effects of itraconazole against Trypanosoma cruzi. Am J Trop Med Hyg 1986; 35: 280-4.

12.- APT W, ARRIBADA A, ZULANTAY I, SÁNCHEZ G et al. Itraconazole or allopurinol in the treatment of chronic American tripanosomiasis: the regression and prevention of electrocardiographic abnormalities during 9 years of follow-up. Ann Trop Med Parasitol 2003; 97: 23-9.

13.- APT W, AGUILERA X, ARRIBADA A et al. Treatment of chronic Chagas disease with Itraconazole and Allpurinol. Am J Trop Med 1998; 59: 133-8.

14.- SCHENONE H, ALFARO E, ROJAS A. Bases y rendimiento del xenodiagnóstico en la infección humana. Bol Chile Parasitol 1974; 29: 24-6.

15.- ZULANTAY I, APT W, RODRÍGUEZ J et al. Evaluación serológica del tratamiento de la enfermedad de Chagas crónica con Alopurinol e Itraconazol. Rev Méd Chile 1998; 126: 265-70.

16.- WINCKER P, BRITTO C, PEREIRA J B et al. Use a simplified polymerase chain reaction procedure to detect Trypanosoma cruzi in blood samples from chronic chagasic patients in a rural endemic area. Am 
J Trop Med Hyg 1994; 51: 771-7.

17.- SOLARI A, ORTIZ S, SOTO A et al Treatment of Trypanosoma cruzi - infected children with nifurtimox: a 3 year follow-up by PCR. J Antimicrob Chemother 2001; 515-19.

18.- ZULANTAY I, HONORES P, SOLARI A et al. Use of polymerase chain reaction (PCR) and hybridization assays to detect Trypanosoma cruzi in chronic chagasic patients treated with itraconazole or allopurinol. Diag Microbiol Inf Dis 2004; 48: 253-7.

19.- VALDÉS J M. Organización y Presupuesto. Taller sobre erradicación o control de la enfermedad de Chagas en Chile. Santiago, Chile. 1991. 70 pág.

20.- MIDEPLAN. Ministerio de Planificación y Cooperación. 1998. Documento 1992-1998. Encuesta CASEN.

21.- MIDEPLAN. Ministerio de Planificación y Cooperación. Situación del Sector Rural en Chile 2000. Documento $\mathrm{N}^{\circ} 7$. Gobierno de Chile. 86 pág.

22.- Comisión Nacional de Energía. La electrificación rural en Chile. Gobierno de Chile. 1992-2002. 16 páginas.

23.- COURA J R, CASTRO S L. A critical Review on Chagas'disease Chemotherapy. Mem. Inst Oswaldo Cruz. Rio de Janeiro 2002; 97(1): 3-24.

24.- BRITTO C, SILVEIRA C, CARDOSO M A et al. Parasite persistence in treated chagasic patients revealed by xenodiagnosis and polymerase chain reaction. Mem Inst Oswaldo Cruz 2001; 96: 823-26.

25.- DE ORNELAS TOLEDO M J, BAHÍA M T, CARNEIRO $\mathrm{C} \mathrm{M}$ et al. Chemotherapy with benznidazole and itraconazole for mice infected with different Trypanosoma cruzi clonal genotypes. Antimicrobial Agents and Chemotherapy 2003; 47: 223-30.

Agradecimientos: Este estudio fue financiado por el Proyecto DI-SAL 09/03, Universidad de Chile y el Instituto de Biotecnología. Facultad de Ciencias. Universidad de Granada. España.

\section{Congreso Latinoamericano de Parasitología IV Congreso Argentino de Parasitología XXIX Jornadas Internacionales de Hidatidología}

La Parasitología y su contribución a una América Latina unida

9 al 12 de noviembre, 2005 - Hotel Costa Galana

Mar del Plata, Buenos Aires, Argentina

\section{Mesas redondas}

\section{Hidatidosis}

Epidemiología de parasitos intestinales

Antiparasitos en medicina veterinaria

Parasitosis y SIDA

Toxoplamosis

Paleoparasitología

Malaria

Leishmaniosis

Parasitosis de organismos acuáticos

Zoonosis parasitarias

Fecha límite de presentación de resúmenes: 15/7/2005 